\title{
THE PRICE OF OPTIONS ILLIQUIDITY
}

\author{
Menachem Brenner, Rafi Eldor, and Shmuel Hauser
}

* Brenner is from the Stern School of Business, New York University. Eldor is from the Arison Business School, IDC, Herzelia. Hauser is from the School of Management, Ben Gurion University, and from the Israel Securities Authority. We would like to thank Yakov Amihud, Orit Halvitz, Bill Silber, Meir Sokoler, Raghu Sundaram, Tony Saunders, Marti Subrahmanyam and Sanjay Unni for their helpful comments and suggestions. Special thanks to Ken Garbade for spending many hours reading and commenting on every draft of this paper. Many thanks to the Bank of Israel and the TelAviv Stock Exchange for providing the data and responding to our innumerable questions. Finally, we thank René Stulz and the referee of this paper for their many helpful comments and suggestions. 


\title{
THE PRICE OF OPTIONS ILLIQUIDITY
}

\begin{abstract}
A B S T R A C T
The purpose of this paper is to examine the effect of illiquidity on the value of currency options. We use a unique data set which allows us to explore this issue in special circumstances where options are issued by a central bank and are not traded prior to maturity. The value of these options is compared to similar options traded on the exchange. We find that the non-tradable options are priced about 21 percent less than the exchange traded options. This gap cannot be arbitraged away due to transactions costs and the risk that the exchange rate will change during the bidding process.
\end{abstract}

One important aspect of research on the micro-structure of financial markets is the effect of liquidity on financial assets. The early micro-structure literature views liquidity as a determinant of transactions costs, affecting the bid-ask spreads but not equilibrium prices. 1 More recent studies that deal with the effect of liquidity on the prices of financial assets present evidence that illiquidity has an adverse effect on asset values (e.g., Amihud and Mendelson (1991) on bond prices, Silber (1991) on restricted stocks, Longstaff (1995) on liquidity, volatility and price). 2

These papers deal with the effect of liquidity on stocks and bonds. How about options? Does illiquidity of an option affect its price? Thus far, to our knowledge, this issue has not been discussed in the micro-structure literature. 3

Though illiquidity in the options market has been mentioned with regard to the bid-ask spread, it has not been discussed in the context of the option price itself, partly due to the fact that the concept of liquidity is not trivial when it comes to options. 4 For example, to price an option in the Black-Scholes world we need a market where the option payoffs can be replicated. Thus, if the market for the underlying asset trades 
continuously (i.e., is liquid) we can price any option, whether it trades continuously or not. If, however, the underlying asset is not very liquid and/or the price process is not a diffusion process (e.g., it is a jump process or one with stochastic volatility) we cannot price the option by replication. Under these circumstances how would an illiquid option fare compared to a liquid option? Should the illiquid option, when issued, command a premium or sell at a discount, compared to the liquid option? In a market where options are created by market participants, illiquid options should sell, if at all, for about the same price as liquid options since buyers will never pay more for illiquid ones and sellers will never sell for less. However, should illiquid options sell for less in case the writer of these (non-tradable) options is a central bank, which sells the options in an auction to the highest bidder? Clearly, if these options could be replicated costlessly with liquid options then they should sell for the same price. Since the liquid options in our case do not have the same characteristics (they differ by strike price and expiration dates), replicating the illiquid options with the liquid ones would generate transactions costs. In such a case, these options should sell at a discount determined mainly by the transactions costs.

The objective of this study is to examine empirically the effect of illiquidity on option values. Are illiquid options selling at a discount? Is the discount fully accounted for by the transactions costs? The Israeli currency market provides a unique opportunity for testing the effect of illiquidity on options prices. There are two types of options on the U.S. dollar (paid in Israeli currency - NIS): options issued and traded on the Tel-Aviv Stock Exchange (TASE) and non-negotiable options sold weekly by the Central Bank of Israel $(\mathrm{BI})$ in sealed bid auctions. The main differences between these two types of options are: (1) While the exchange traded (ET) options are created by market participants and everyone is a potential buyer or writer, the sole writer of the $\mathrm{BI}$ options 
is the central bank; and (2) the ET options are continuously traded while the central bank options are issued in an auction and can not be traded prior to expiration. ${ }^{5}$

The remainder of the paper is organized as follows. Section I describes the data and the methodology. In Section II we present and discuss the results of the statistical tests. The main findings are summarized in Section III.

\section{Data and Methodology}

\section{1st. Data}

The sample period starts with the inception of trading in currency options on the

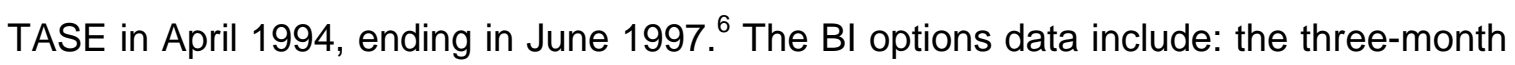
at-the-money (ATM) call options for the corresponding period, the three-month at-themoney-forward (ATMF) calls and the six-month ATMF calls. The BI option prices that we use are the average price in each auction. The ET options have fixed exercise prices at .05 spreads (e.g., $\mathrm{K}=3.45, \mathrm{~K}=3.50, \mathrm{~K}=3.55$ ) and a given calendar expiration date, while the $\mathrm{BI}$ options are always issued ATMF, or ATM, with 90 or 180 days to expiration. Only on rare occasions will the expiration date and/or the exercise price of the two options match.

The total number of observations of $\mathrm{BI}$ options is 566.272 of those are ATMF options with 90 days to expiration, 127 are ATMF options with 180 days to expiration and 167 of them are ATM options with 90 days to expiration. ${ }^{2}$ For the ET options we used the transaction prices of trades done on the same days that auctions were held (Tuesdays and Thursdays) ${ }^{8}$ In addition to the option premium (price), we also collected the daily NIS/\$ exchange rate, the domestic short term interest rate and the three-month Euro-dollar rate. Other inputs are given by the specification of the option contracts. The BI options data were obtained from the Bank of Israel and the ET options data were obtained from the TASE. 
An important aspect of the data is the auction process. The $\mathrm{Bl}$ options are issued in a sealed-bid discriminating auction. The process starts at 9:00 a.m. with an electronic announcement of the central bank to all banks on the details of the auction, notional amount, strike price, days to expiration, and minimum bidding price. This announcement goes out immediately from the banks to all their clients. By 11:00 a.m. all interested clients submit their bids through their banks (branch offices) directly to the central bank. At the same time, the banks submit their bids for their own account, independent of the

branch offices, to the central bank ${ }^{9}$ The results are known within half an hour (used to be one hour). Since only the banks can participate in the auction, the clients pay a commission, charged by the banks, of 0.25 percent-0.50 percent (lower for preferred clients) of the options premium. Every bank is submitting the bids of many clients such that in every auction there are potentially many participants (the Bank of Israel is not making public the number of bids submitted by all the banks). The options cannot be traded prior to maturity and the sole writer is the Bank of Israel. During the sample period the daily average notional amount was 5.27 million dollars for the $\mathrm{BI}$ options and 9.98 million dollars for the Exchange traded (ET) options.

\section{B. Methodology}

Our objective is to study the effect of illiquidity on option prices. Is an illiquid option valued less than a corresponding liquid option? The answer to this question is not clear since both, the writer and the buyer, face the same problem, lack of liquidity. If, however, we can identify clearly the options' writers and claim that they are indifferent to liquidity but the buyers are not, then it can be argued that the price should be lower the less liquid the option is. This discount, however, should be a function of the extent to which one can replicate the payoffs of the illiquid option. The non-tradable BI options 
provide a unique opportunity to test the effect of liquidity on options' prices compared to the ET liquid options.

The options offered by the Bank of Israel are issued in an auction process where the bank is a passive writer and their premiums should reflect the buyers concern with them being non-tradable. It can be argued that the options buyers could write similar ET options to lock-in arbitrage profits. However, a perfect arbitrage, which is riskless to expiration, is possible only if the ET options have exactly the same characteristics as the BI options. Since they differ by strike prices and time to maturity, the only possible arbitrage is to replicate the $\mathrm{BI}$ options with the $\mathrm{ET}$ options and rebalance the position as the market changes. The replication is costly and therefore should be reflected in the discount.

The difference in strike prices and time to maturity requires special care when the $\mathrm{BI}$ options are compared to the ET options. To deal with this problem we start with a simple test, which we consider an indication test, that compares the Implied Standard Deviations (ISD) computed from the ET options to those computed from the BI options. We use the same parameters for both options on days that the $\mathrm{BI}$ options are issued except for strike prices and days to expiration. The ISD is weighted by vega in the following way:

$$
W I S D=\sum_{i=1}^{n} W_{i} I S D_{i}
$$

where $\mathrm{n}$ is the number of ET options at date $\mathrm{t}, W_{i}=W_{i}^{*} / \sum_{i=1}^{n} W_{i}^{*}, W_{i}^{*}=\partial C_{i} / \partial \sigma_{i}$ and $I S D_{i}$ is the ISD from option i;

The justification for vega weighting is as follows. Since at-the-money options are more liquid than away from the money, we used a weighting scheme that gives larger weight to at-the-money options, which are more sensitive to volatility. Also, the larger weight given to at-the-money options reduces the effect, if any, of a volatility "smile". 
The results of our initial test, are presented in Table I which compares the Implied Standard Deviations (ISD) computed from the ET options to those computed from the Bl options. ${ }^{10}$

\section{Insert Table I here}

The mean ISD (and the median) of the $\mathrm{BI}$ options is significantly lower than the ET options, 0.0492 vs. 0.0639 , using the entire sample. Note that while the ATMF options show a difference of 1.5 percent to 1.7 percent on average, the ATM options show a smaller difference, about 1.2 percent. One possible explanation that the ATM options show less of a deviation than the ATMF options is the presence of a selection bias. While in all auctions (except nine) for three-month ATMF options and for six-month ATMF options there were bidders (in most cases the demand was much larger than the supply), in about 40 percent of the ATM options there were no bidders. The main reason that there were not many bidders for these options was the fact that, given the high interest rate differential between the domestic and the foreign rate, the ATM options were in fact deep-in-the-money options and most clients were not interested in options that were practically forward contracts. ${ }^{11}$ A second reason was the difference in the minimum price that was set for the ATM options and ATMF options. When we examined the minimum price series for both options, we found that the minimum price of the ATMF options implied, on the average, a volatility of 4 percent while the minimum price set for the ATM options in many cases implied a volatility of almost 6 percent. For these reasons there was less interest in the ATM options. Thus, the ATM options are a biased sample since they exclude all potential participants who did not bid because of the above mentioned reasons. The ATMF options, on the other hand, had most of the time demand much larger than the amount offered by the Bank of Israel. We show later that 
the demand for the ATMF options was about four times larger, on the average, than the amount offered. We, therefore, focus on the ATMF options in the tests that follow.

The problem with the use of implied standard deviations is that the assumptions of the B-S model do not strictly hold. In particular, the assumption of a log-normal distribution of the underlying asset and the requirement that all securities trade continuously. We argue that the dynamics of the exchange rate (NIS/US\$) in our sample has a negligible effect on the empirical results for the following reasons. First, the exchange rate bands, imposed by the central bank, are on a basket of currencies including the dollar. Although the dollar's weight in the basket is about 55 percent, the band is not as restrictive vis-á-vis the dollar. Second, empirical evidence indicates that for bands larger than 10 percent, the value of at-the-money options is only slightly different from the B-S value which assumes no FX bands (see Ingersoll (1997)). Third, in a study on the Israeli currency market Samer HajYehia (1997) claims that the B-S model is robust to the NIS $/$ exchange rate dynamics during the sample period that we used.

In an attempt to deal with the dynamics of the exchange rate, especially the issue of FX bands which is not consistent with a B-S environment, we use two alternative methods. In both methods, we compare the premium of the $\mathrm{BI}$ options to a synthetic premium obtained from the ET options. While the first method uses the ISD of ET options to compute the synthetic option price, which is similar to comparing the ISDs, the second method uses the B-S model to compute only the weight, in creating the synthetic price, such that the effect of the B-S model on our test is minimal.

\section{B.1 Method 1}

The first method is illustrated with option prices recorded on June 18, 1996. Table II provides an example using two exchange traded options which differ by maturity 
only. These options straddle the maturity of the $\mathrm{BI}$ options which are issued with three months to maturity. We use their ISD to compute a weighted ISD and use this figure as an input to compute the "theoretical" price of the BI options. The auction price of the $\mathrm{BI}$ option (0.0438 NIS per 1 \$US), on June 18, 1996, is compared to the synthetic option (0.0501 NIS per 1 \$US). In this example, the percentage difference is interpreted as the price of illiquidity or "Illiquidity Discount," which is about 12.6 percent (i.e., the price of the illiquid option, the $\mathrm{BI}$ option, is 12.6 perecent lower than the price of the ET liquid option).

Insert Table II about here

\section{B.2 Method 2}

The second method is designed to deal with the concern that the results of our test may depend upon the model used. We follow a method offered by Brenner and Galai (1993) which allows us to estimate the illiquidity discount in a manner which is minimally dependent upon the B-S model. The test uses more information then the previous method to create a 90 day ATMF synthetic call interpolated from prices of calls from four series with weights based on the BS model. We use two shorter-term call options with strike prices that bracket the strike price of the $\mathrm{Bl}$ option and two longerterm call options with strike prices that similarly bracket the strike prices of the $\mathrm{BI}$ options. We then create two synthetic calls, which are close to the money, and finally combine the two to create a 90 day ATMF synthetic call as follows.

Denote the currency forward exchange rate by $S e^{\left(r-r^{*}\right) T}$, the strike prices by $\mathrm{K}_{1}$ and $\mathrm{K}_{2}$, where $\mathrm{K}_{1}<S e^{\left(r-r^{*}\right) T}<\mathrm{K}_{2} . \quad \mathrm{C}^{\mathrm{A}}$ and $\mathrm{C}^{\mathrm{M}}$ are the actual $(\mathrm{A})$ and model $(\mathrm{M})$ prices. First, we compute

$$
C\left(T=90, K_{1}\right)=C_{1}^{A}\left(K_{1}\right) w+C_{2}^{A}\left(K_{1}\right)(1-w)
$$


Where, $C_{1}^{A}\left(K_{1}\right)$ is the actual price of the short maturity option, $C_{2}^{A}\left(K_{1}\right)$ is the actual price of the long maturity option and

$$
w=\frac{C^{M}\left(T=90, K_{1}\right)-C_{2}^{M}\left(K_{1}\right)}{C_{1}^{M}\left(K_{1}\right)-C_{2}^{M}\left(K_{1}\right)}
$$

where the weight $w$ is based on model prices for the corresponding short, long and 90 day maturities and $C_{1}^{A}\left(T=90, K_{1}\right)$ is the value of a 90 day call with the strike $K_{1}$. The model prices use the at-the-money implied volatility.

Second, we repeat this procedure to compute $C\left(T=90, K_{2}\right)$. We then combine these two synthetic calls to compute our synthetic ATMF 90 days call option, denoted $C^{*}$

$$
C^{*}=C\left(T=90, K_{1}\right) v+C\left(T=90, K_{2}\right)(1-v)
$$

Where

$$
v=\frac{C^{M}\left(T=90, K=S e^{\left(r-r^{*}\right) T}\right)-C^{M}\left(T=90, K_{2}\right)}{C^{M}\left(T=90, K_{1}\right)-C^{M}\left(T=90, K_{2}\right)}
$$

and $C^{*}$ is a synthetic option created from ET options which is compared to the $\mathrm{BI}$ option. Thus, according to this method we take a weighted average of four ET options to create a synthetic price which is compared to the price of the BI option.

\section{Results}

\section{A. The Illiquidity Discount: Method 1}

The main hypothesis is that non-tradable options should be priced lower than similar liquid options. In Table I we have used the B-S model to compute the implied standard deviations and compared them. Another way to measure and present the 
results of this test is to compare the untransformed $\mathrm{Bl}$ options premiums to those of synthetic options based on the prices of the ET options.

We follow the procedure outlined in Table II where we compute the value of an option that has the same exercise price and maturity as that of the BI option but uses the volatility implied by TASE options. This model value is compared to the auction price of the $\mathrm{Bl}$ option. We then compute the illiquidity discounts (ILD), measured by the percentage difference in option premiums between ET options and the non-tradable BI options. Table III displays the results of the illiquidity discount. Since WISD, using vega weighting, may not fully compensate for the possibility of the known volatility "smile", we have used three estimates of volatility. Only the first alternative (column I) uses vega weighting across strike prices and maturities based on all ET options traded on day t. The second alternative (column II) uses vega weighting across strike prices only, based on three ET options closest to ATMF and closest to maturity of the BI options, which is effectively similar to equal weighting. The third alternative (column III) uses only one option (no weighting at all) that its strike price is the closest to ATMF and is the closest in maturity.

We find that the $\mathrm{BI}$ option price is on the average about 21 perecent lower than the ET option price (column 1). The smallest difference, obtained in the most recent period is about 17 percent. Similar results were obtained when we used alternative estimates of volatility displayed in columns II and III. It seems that the illiquidity discount is insensitive to the method of estimating the volatility. ${ }^{13}$ All the results are statistically significant at the one perecent level.

When we examined the change from the earlier period (1994 to 1995) to the latter period (1996 to 1997) we observe that on average, there was a decline in the illiquidity discount that could be related to the increased liquidity in the FX spot and FX options markets. The increased liquidity in these markets is a result of a change in the 
central bank intervention policy (to non-intervention inside the FX band) combined with lower transactions costs for trading options. 14

Insert Table III here

In Table IV we present the results by option maturity as auctioned by the Bank of Israel. We use the same method as in Table III (method 1). Here we find that both the three and six- month ATMF options are discounted by about 21 percent compared to the ET options. The null hypothesis of zero difference, no liquidity discount, is rejected at the one percent level for both types of options. Here too we observe a decline in the discount from 26.5 percent in the early period (1994 to 1995) to 16.7 percent in the later period (1996 to 1997). 15

\section{Insert Table IV about here}

Another indication that the discount that we find is due to the illiquidity of the $\mathrm{BI}$ options is the relationship between volatility and the illiquidity discount (see, for example, Longstaff (1995)). We have tested this relationship by regressing the illiquidity discount (ILD) against the implied volatility (ISD). The results are:

$$
I L D_{i}=-0.04325+4.0024 I S D_{i} \quad R^{2}=21.1 \%
$$

The numbers in parenthesis are p-values. We use the ISD of an exchange option that is the closest in maturity and strike price to the $\mathrm{Bl}$ option. Though the variation in the implied volatility is not large, we found a positive and significant relationship. 16 


\section{B. Illiquidity Discount: Method 2}

In the next test we examine the robustness of the results to the method used. We estimate the illiquidity discount in an alternative way, described in the previous section (method 2). This method uses two short-term call options with strike prices that bracket the forward price and similar two next-term call options. We then create two synthetic calls, which are close to the money, and combine the two to create a 90 days ATMF synthetic call. The value of this call is compared to the premium paid on the option issued by the central bank.

Insert Table $\mathrm{V}$ about here

Table $\mathrm{V}$ presents the mean percentage difference between the synthetic options, based on ET options data, and the BI options. The results are consistent with the earlier results. For the entire sample period the mean difference is about 19.4 percent and is significant at the 1 percent level. In the most recent period the difference is still highly significant, but lower, about 15 percent. The results of method 2 are indistinguishable from the results of method 1 .

\section{Illiquidity Discount and Transaction Costs}

In this section we examine whether the cost of replication could fully account for the 21 percent discount. A well designed arbitrage would require replicating the $\mathrm{BI}$ option with the lowest possible costs. Since any replication of the $\mathrm{BI}$ options is not perfect, dynamic replication will incur some costs. Since in this market, selling and buying foreign exchange funds is more costly than selling and buying options, we replicate the $\mathrm{BI}$ options with $\mathrm{ET}$ options. The replication method is as follows: when a BI option is offered we calculate the option's delta using WISD of the three closest ATMF exchange traded options with the closest expiration date, computed on the same day. 
Against the $\mathrm{BI}$ option that we buy in the auction, we sell on the first day $x_{t}$ of ET options that result in a delta neutral position. From then on, we recalculate the BI option's delta, each day, in the same manner and sell or buy $\Delta x_{t}$ of ET options to regain a delta neutral position. The transactions costs incurred using this replicating procedure amount to $1.5 \sum_{t=1}^{T}\left|\Delta x_{t}\right|$ when there are $\mathrm{T}$ days to expiration. The $1.5 \mathrm{NIS}$ is the cost of buying or selling ET options by members of the exchange, paid to the clearing corporation. The percentage transactions costs is estimated by $1.5 \sum_{t=1}^{T}\left|\Delta x_{t}\right| / C_{B I}$, where $C_{B I}$ is the $\mathrm{BI}$ call price. The idea is to maintain a combined position that is essentially riskless. In doing so we incur transactions costs, which account for 12 percent out of the 21 percent. These results are presented in Table VI. The remaining gap, about nine percent, is still significantly large and is about the same in the most recent period. This gap can be explained by the uncertainty associated with the time span between the submission of the bid and the announcement of the winners (between half an hour to an hour). An indication that this is the case is given by the significant positive relationship between the illiquidity discount (ILD) and implied volatility reported earlier. This relationship suggests that when the volatility is larger, arbitragers are more concerned about the move of the exchange rate during the time gap and therefore they demand a larger discount. Also, there is no evidence of excessive arbitrage activity on auction expiration days compared with other days. ${ }^{17}$ This is another indication that the 9 percent remaining gap is due to the uncertainty mentioned above.

\section{Insert Table VI about here}

\section{The Illiquidity Discount and the Auction Process}

How competitive is the bidding process and to what extent does the auction process drive these sizable discounts? To address this question we first examined the auction data regarding the rate of over- and undersubscription at the Bank of Israel 
auctions. The rate of subscription is measured by the amount of options demanded divided by the amount of options offered. In Table VII we find that across all 399 auctions, the mean rate of subscription is 3.92 (the median is 4.2 ). The maximum is over 10 and the minimum is 2 percent. 83 percent of the auctions are oversubscribed.

Insert Table VII about here

Another indication of the competitevness of the auction process is the deviation of the minimum price $\left(C_{B I}^{M I N}\right)$ set for each auction from the average auction price $\left(C_{B I}\right)$. In Table VIII, we find that for the overall sample, $C_{B I}^{M I N}$ is 17 percent lower than $C_{B I}$. We also find that it is 35 percent lower than $C_{E T}$. The results in both tables cannot explain the large discounts and do not support the possibility that the discounts are driven by the auction process.

\section{Insert Table VIII about here}

Nevertheless, the fact that 17 percent of the auctions were under-subscribed and that the deviation, $C_{B I}^{M I N}$ from $C_{B I}$, ranges from six percent in the early period to 31 percent in the third period may still indicate that the discounts may be an outcome of the auction process. Because of this concern, we examined the relationship between the discount (ILD) and the rate of subscription (RS) using a regression test. If the discounts are a result of the auction process we should find a negative relationship between $R S$ and $I L D$. The following results show that there is no significant relationship between ILD and $R S$.

$$
I L D_{i}=0.1972+0.0034 R S_{i} \quad R^{2}=0.3 \%
$$


Moreover, we computed the average discount for all auctions which were oversubscribed (333) and for those that were undersubscribed (66). The average discount is larger (21.6 percent) for the over-subscribed than the average discount for the under-subscribed (18.1 percent). These results provide further evidence that the observed discounts are not driven by the auction process.

\section{Summary and Conclusions}

Given the growing interest among academics and practitioners in the effect of liquidity on the values of financial assets, we examine here the effect of illiquidity on the value of currency options. In the standard case, illiquidity should not affect a derivative asset since options are a zero-sum game. In this paper, however, we use a unique data set that allows us to explore this issue in circumstances where the question is relevant. We look at currency options issued by a central bank that are not traded until maturity. We argue that prices of such options may be affected by illiquidity. We test our hypothesis by comparing these options to similar exchange traded options. The results are significant in all cases. We reject the hypothesis that liquidity has no effect on the price of the options. We find that the non-tradable options are discounted by about 21 percent on the average. There was, however, a gradual decline in the discount from 27 percent in the first period to about 17 percent in the last period. In general, illiquid options should not be selling at a discount even when the underlying asset is not liquid. The exception is in cases when the options are sold at an auction, as done by some central banks. The discount should be a function of the cost of replicating the illiquid option. In our case the discount can be explained by transactions costs associated with replication and by the time gap during the bidding process. 


\section{Appendix}

\section{The Currency Market in Israel}

\section{A. The Spot and Forward Currency Market}

The Israeli Foreign Exchange market has undergone a major transformation in recent years, from a market largely controlled by the central bank, to an active interbank market which trades continuously but not in a large volume. However, due to several restrictions imposed by the central bank, ${ }^{18}$ market participants are mainly corporations who use foreign exchange in their transactions. The banks act as "market makers" since all transactions must go through them. At the end of each trading day the central bank publishes a settlement (representative) exchange rate for each currency that is based on the quotes obtained from the major banks. This is used in settling options at expiration.

Since the early 1990's the exchange rate regime was a "crawling" peg system. In this regime a band was imposed around an upward sloping exchange rate, on a basket of five currencies, reflecting the difference in inflation between Israel and the "basket" economies. The central bank is committed to intervene only when the band is breached. In May 1995, the width of the band was increased from 10 percent to 14 percent and in June 1997 it was increased again to 30 percent. Also, until February 1996, the central bank intervened occasionally in the FX market to keep the exchange rate around the center of the band. It stopped its intervention on February 16, 1996. In our tests we have divided the whole sample period into three subperiods in line with the changes in the policy of the central bank. The second subperiod starts when the FX band was increased from 10 percent to 14 percent. The third subperiod starts when the central bank stopped its intervention inside the exchange rate band. 


\section{B. Currency Options on the TASE}

Currency options on the TASE started trading on April 1, 1994. In the first 20 months, the volume of trading was not high and amounted to 400 contracts a day, on the average. During 1996, the daily volume increased dramatically from 331 contracts in January to 5,674 in December of that year. Open interest increased over the same interval, from 10,677 contracts in the beginning of the year to 168,212 contracts in December.

The underlying asset is the dollar denominated in shekel (the domestic currency). The options are European puts and calls. They are cash settled, where the settlement price is the so-called "representative" exchange rate published daily by the Bank of Israel. The maturity cycle is two, four and six months.

The options are traded by members of the TASE in an open outcry system, with about 20 to 30 traders in the pit, governed by rules and regulations set by the Exchange. There is no designated market maker that is committed to quote prices. The tick size for options with a premium of 200 to 2,000 NIS is 10 NIS, and is 20 NIS for larger than 2,000 NIS. The premium for a wide range of options around the money, an average of 90-day maturity and a volatility of 5 percent to 10 percent are in the range of 200-1000. Over 80 percent of the trades in these options are done within one tick, implying that the effective bid-ask spread is one tick.

\section{Options Issued by the Bank of Israel}

The Bank of Israel (BI) started issuing call options (European type) on the dollar in November 1989. Initially, the main reason that the central bank engaged in this activity was to enhance the development of the markets for derivatives in Israel. At that time no other derivative was traded on the Stock Exchange. 
There are two classes of three-month (13 weeks) options auctioned twice a week (Tuesday and Thursday). They are issued with two strike prices; exactly at-the-moneyforward (ATMF) and at-the-money (ATM). They also expire on Tuesdays and Thursdays. A six-month (26 weeks) at-the-money forward option is auctioned once a week (Thursday). In all auctions, there is a floor (minimum) price which is typically set below the comparable price on exchange traded options. 


\section{REFERENCES}

Amihud, Yakov, and Haim Mendelson, 1991, Liquidity, maturity and the yields on U.S. government securities, Journal of Finance 46, 1411-1426.

Amihud, Yakov, Haim Mendelson, and Beni Lauterbach, 1997, Market microstructure and securities values: Evidence from the Tel Aviv Stock Exchange, Journal of Financial Economics 45, 365-395.

Boyle, Phelim P., and Ton Vorst, 1992, Option replication in discrete time with transaction costs, Journal of Finance 47, 271-294.

Brenner, Menachem, and Dan Galai, 1993, Hedging volatility in foreign currencies, The Journal of Derivatives 1, 53-59.

Christie, William G., and Roger D. Huang, 1994, Market structure and liquidity: A transactions data study of exchange listings, Journal of Financial Intermediation 3, 300-326.

Demsetz, Harold, 1968, The Cost of Transacting, Quarterly Journal of Economics 82, 33-53.

HajYehia, Samer, November 1997, The Israeli currency option market: 1991-1996, MA dissertation, Hebrew University, School of Business.

Huang, Roger D., and Hans R. Stoll, 1996, Dealer versus auction markets: A paired comparison of execution costs on Nasdaq and the NYSE, Journal of Financial Economics 41, 313- 357.

Ingersoll, Jonathan. E., 1997, Valuing foreign exchange rate derivatives with a bounded Exchange process, Review of Derivatives Research 1, 159-181.

Kadlec, Gregory B., and John J. McConnell, 1994, The effect of market segmentation and illiquidity on asset prices: evidence from exchange listings, Journal of Finance 49, 611-636. 
Leland, Hayne, 1985, Option pricing and replication with transaction costs, Journal of Finance 40, 1283-1301.

Longstaff, Francis A., 1995, How much can marketability affect security values? Journal of Finance, 50, 1767-1774.

Silber, William., 1991, Discounts on restricted stock: The impact of illiquidity on stock prices, Financial Analysts Journal 47, 60-64.

Toft, Klaus, B., 1994, Exact formulas for expected hedging errors and transaction costs in option replication, Working Paper, University of California. 


\section{Table I}

\section{Sample Statistics of Weighted Implied Standard Deviations (WISD)}

The weighted standard deviation is computed as follows: WISD $=\sum_{i=1}^{n} w_{i} I S D_{i}$ where ISD is the implied standard deviation from previous day market call prices, $w_{i}=w_{i}^{*} / \sum_{i=1}^{n} w_{i}^{*}$ and $w_{i}^{*}=\partial C_{i} / \partial I S D_{i}$. The exchange traded (ET) WISD is computed using all options traded on auction days on the Tel-Aviv Stock Exchange (TASE). The Bank of Israel (BI) WISD is computed using all options auctioned in the sample period, December 4, 1994 to June 30, 1997. Diff. represents the average differences between ISDs for each day BI option was auctioned. A $p$-value for the differences in means is based on a t-test. A p-value for the differences in medians is based on a Kruskal-Wallis (KW) non-parametric test.

\begin{tabular}{|c|c|c|c|c|c|}
\hline & Mean & Median & S.D. & Maximum & Minimum \\
\hline \multicolumn{6}{|c|}{ All Sample $(n=566)$} \\
\hline TASE & 0.0693 & 0.0629 & 0.0147 & 0.1335 & 0.0342 \\
\hline Bank Of Israel & 0.0492 & 0.0474 & 0.0122 & 0.1173 & 0.0230 \\
\hline Diff. & 0.0148 & 0.0147 & 0.0116 & 0.0605 & -0.0199 \\
\hline p-value & $(0.000)$ & $(0.000)$ & & & \\
\hline \multicolumn{6}{|c|}{ Three-month ATM (n=167) } \\
\hline TASE & 0.0653 & 0.0638 & 0.0154 & 0.1335 & 0.0342 \\
\hline Bank Of Israel & 0.0535 & 0.0525 & 0.0138 & 0.1773 & 0.0264 \\
\hline Diff. & 0.0118 & 0.0113 & 0.0132 & 0.0605 & -0.0199 \\
\hline p-value & $(0.000)$ & $(0.000)$ & & & \\
\hline \multicolumn{6}{|c|}{ Three-month ATMF $(n=272)$} \\
\hline TASE & 0.0625 & 0.0611 & 0.0146 & 0.1335 & 0.0342 \\
\hline Bank Of Israel & 0.0470 & 0.0445 & 0.0117 & 0.0921 & 0.0231 \\
\hline Diff. & 0.0155 & 0.0149 & 0.0103 & 0.0563 & -0.0065 \\
\hline$p$-value & $(0.000)$ & $(0.000)$ & & & \\
\hline \multicolumn{6}{|c|}{ Six-month ATMF $(n=127)$} \\
\hline TASE & 0.0653 & 0.0637 & 0.0139 & 0.1062 & 0.0349 \\
\hline Bank Of Israel & 0.0482 & 0.0455 & 0.0102 & 0.0755 & 0.0249 \\
\hline Diff. & 0.0171 & 0.0165 & 0.0111 & 0.0516 & -0.0056 \\
\hline p-value & $(0.000)$ & $(0.000)$ & & & \\
\hline
\end{tabular}




\section{Table II}

\section{The Difference Between the Price of an Exchange Traded Option and the Price of a Bank of Israel Option: An Example}

The example is based on two options traded on the Tel-Aviv Stock Exchange (TASE) on June 18, 1996 and their terms $(\mathrm{K}, \mathrm{T})$ are the closest to the Bank of Israel $(\mathrm{BI})$ options. The inputs were: $\mathrm{S}=$ $3.261(\mathrm{NIS} / \$), r_{I S}=16.9$ percent, $r_{U S}=5.4$ percent where $\mathrm{S}$ is the exchange rate, $r_{I S}$ is the yield on an Israeli three-month T-bill and $r_{U S}$ is the yield on a U.S. three-month T-bill. We computed a weighted implied standard deviation (WISD) using two at-the-monry options traded on the exchange. This WISD was used in computing the price of the synthetic exchange traded (ET) option. The percentage difference between the Central Bank of Israel (BI) option price and the synthetic ("market”) ET price is what we call "price of illiquidity" or Illiquidity Discount (ILD).

\begin{tabular}{|c|c|c|c|c|}
\hline & $\begin{array}{l}\text { Option } \\
\text { Price }\end{array}$ & $\begin{array}{l}\text { Time to } \\
\text { Expiration }\end{array}$ & $\begin{array}{c}\text { Exercise } \\
\text { Price }\end{array}$ & $\begin{array}{c}\text { Implied } \\
\text { standard } \\
\text { deviation }\end{array}$ \\
\hline \multicolumn{5}{|l|}{ TASE } \\
\hline Option 1 & 0.117 & 144 days & 3.30 & $6.03 \%$ \\
\hline Option 2 & 0.061 & 71 days & 3.30 & $7.47 \%$ \\
\hline Bank of Israel Option & 0.0438 & 91 days & 3.34 & \\
\hline Exchange 'market' price & 0.0501 & 91 days & 3.34 & $6.66 \%$ \\
\hline Price of illiquidity & \multicolumn{4}{|c|}{$\operatorname{ILD}=\left|0.0438 / 0.0501^{-1}\right|=0.126$} \\
\hline
\end{tabular}




\section{Table III}

\section{The Effect of Liquidity on the Pricing of Currency Options - Method 1}

The average illiquidity discount (ILD) is measured by the percentage difference between the price of an option traded on the Tel-Aviv Stock Exchange (TASE), $C_{E T}$, and that issued by the Bank of Israel, $C_{B}$, using method 1 (Table II).

$$
\mathrm{ILD}=\left|C_{B I} / C_{E T}-1\right|
$$

The numbers presented in column I are based on weighted impkied standard deviation (WISD) using the closing prices of all options traded on the exchange in the previous day. The numbers presented in column II are based on WISD using the three closest at-the-money options traded on the TASE in the same day. The numbers presented in column III are based on ISD using the closest at-the-money option traded on the exchange. In the last two columns, the options used are also those with the closest time to expiration of the option issued by the Bank of Israel on that day. All ILDs are significantly different from zero at the one percent level.

\begin{tabular}{|c|c|c|c|c|c|c|c|c|}
\hline & & \multirow{3}{*}{$\mathrm{N}$} & \multicolumn{6}{|c|}{ Illiquidity Discount } \\
\hline \multicolumn{2}{|c|}{ Period } & & \multicolumn{2}{|c|}{ I } & \multicolumn{2}{|c|}{ II } & \multicolumn{2}{|c|}{ III } \\
\hline From & To & & Mean & S.D. & Mean & S.D. & Mean & S.D. \\
\hline All Sam & & 399 & 0.210 & 0.104 & 0.204 & 0.125 & 0.181 & 0.127 \\
\hline $4 / 12 / 94$ & $5 / 15 / 95$ & 132 & 0.274 & 0.102 & 0.297 & 0.116 & 0.231 & 0.151 \\
\hline 5/16/95 & 2/15/96 & 111 & 0.189 & 0.109 & 0.195 & 0,117 & 0.151 & 0.132 \\
\hline 2/16/96 & $6 / 30 / 97$ & 156 & 0.171 & 0.073 & 0.148 & 0.092 & 0.160 & 0.079 \\
\hline
\end{tabular}




\section{Table IV}

\section{The Effect of Illiquidity on the Pricing of Currency Options - Method 1 by Option Type}

In this Table we present the average illiquidity discount, ILD, which is measured by the percentage difference between the price of an option traded on the Tel-Aviv Stock Exchange (TASE), $C_{E T}$, and that issued by the Bank of Israel, $C_{B}$, using method 1 (Table II).

$$
\operatorname{ILD}=\left|C_{B I} / C_{E T}-1\right|
$$

The numbers presented are based on WISD using the three most at-the-money options traded on the TASE in the previous day. The numbers presented in column I are the illiquidity discounts of at-themoney-forward options issued by the Bank of Israel with three months to maturity. The numbers presented in column II are the illiquidity discount of at-the-money-forward options issued by the Bank of Israel with six months to maturity. All ILDs are significantly different from zero at the one percent level.

\begin{tabular}{|c|c|c|c|c|c|c|c|}
\hline \multirow{2}{*}{\multicolumn{2}{|c|}{ Period }} & \multicolumn{6}{|c|}{ Illiquidity Discount } \\
\hline & & \multicolumn{4}{|c|}{ I three-month ATMF } & \multicolumn{2}{|c|}{ II six-month ATMF } \\
\hline From & To & $\mathrm{N}$ & Mean & S.D. & $\mathrm{N}$ & Mean & S.D. \\
\hline All Sample & & 272 & 0.210 & 0.105 & 127 & 0.211 & 0.174 \\
\hline $4 / 12 / 94$ & 5/15/95 & 98 & 0.265 & 0.106 & 34 & 0.302 & 0.086 \\
\hline 5/16/95 & 2/15/96 & 73 & 0.197 & 0.111 & 38 & 0.174 & 0.106 \\
\hline 2/16/96 & $6 / 30 / 97$ & 101 & 0.167 & 0.071 & 55 & 0.180 & 0.076 \\
\hline
\end{tabular}




\section{Table V}

\section{The Effect of Liquidity on the Pricing of Currency Options - Method 2}

The average illiquidity discount (ILD) measured by the percentage difference between the price of an option traded on the Tel-Aviv Stock Echange (TASE), $C_{E T}$, and the one issued by the Bank of Israel $(\mathrm{BI}), C_{B l}$, using method 2 described in Section II. The $\mathrm{BI}$ at-the-moneyforward (ATMF) option is compared to a synthetic call option which is obtained by interpolating four series of exchange traded (ET) options with weights based on the BlackScholes model. The number of observations shrinks to $165 \mathrm{BI}$ options (auctions) since we could not always obtain all four series of ET options especially for the six-month ATMF. All mean ILDs are significantly different from zero at the one percent level.

\begin{tabular}{|c|c|c|c|c|}
\hline \multicolumn{2}{|c|}{ Period } & \multirow[b]{2}{*}{$\mathrm{N}$} & \multicolumn{2}{|c|}{ IIlliquidity Discount } \\
\hline From & To & & Mean & S.D. \\
\hline All Sample & & 165 & 0.194 & 0.098 \\
\hline $4 / 12 / 94$ & 5/15/95 & 56 & 0.240 & 0.111 \\
\hline $5 / 16 / 95$ & $2 / 15 / 96$ & 37 & 0.212 & 0.098 \\
\hline $2 / 16 / 96$ & $6 / 30 / 97$ & 72 & 0.150 & 0.064 \\
\hline
\end{tabular}




\section{Table VI}

\section{The Illiquidity Discount and Transactions costs}

Transactions costs are calculated by replicating the Bank of Israel (BI) options with exchange traded (ET) options in the following way. When a $\mathrm{Bl}$ option is offered we calculate the option's delta using weighted implied standard deviation (WISD) of the three closest at-the-money-forward (ATMF) ET options at day t-1. Against the BI option we sell on the first day $x_{t}$ ET options which results in a delta neutral position. Each day, we recalculate the $\mathrm{BI}$ option's delta in the same manner and sell or buy $\Delta x_{t}$ to regain a delta neutral position. The transaction costs incurred using this replicating procedure amounts to $1.5 \sum_{t=1}^{T}\left|\Delta x_{t}\right|$ when there are $\mathrm{T}$ days to expiration assuming that buying or selling an ET option costs $1.5 \mathrm{NIS}$. The percentage transaction cost is estimated by $1.5 \sum_{t=1}^{T}\left|\Delta x_{t}\right| / C_{B I}$.

\begin{tabular}{|c|c|c|c|c|}
\hline \multicolumn{2}{|c|}{ Period } & \multirow[b]{2}{*}{$\mathrm{N}$} & \multicolumn{2}{|c|}{ IIlliquidity Discount } \\
\hline From & To & & Mean & S.D. \\
\hline All Sample & & 319 & 0.1246 & 0.0846 \\
\hline $4 / 12 / 94$ & 5/15/95 & 114 & 0.1327 & 0.0644 \\
\hline $5 / 16 / 95$ & 2/15/96 & 99 & 0.1631 & 0.1148 \\
\hline 2/16/96 & $6 / 30 / 97$ & 106 & 0.0804 & 0.0378 \\
\hline
\end{tabular}


Table VII

\section{The Rate of Subscription at Bank of Israel Auctions}

Rate of subscription is calculated as a ratio of the amount of options demanded at the auctions divided by the amount offered. Number of undersubscribed represents the number of times the auctions were undersubscribed.

\begin{tabular}{|c|c|c|c|c|c|c|c|c|}
\hline \multicolumn{2}{|c|}{ Period } & \multirow[b]{2}{*}{$\mathrm{N}$} & \multirow[b]{2}{*}{ Mean } & \multirow[b]{2}{*}{ S.D. } & \multirow[b]{2}{*}{ Median } & \multirow[b]{2}{*}{ Min } & \multirow[b]{2}{*}{ Max } & \multirow{2}{*}{$\begin{array}{c}\text { No. of } \\
\text { under } \\
\text { Subscribed }\end{array}$} \\
\hline From & To & & & & & & & \\
\hline \multicolumn{2}{|c|}{ All Sample } & 399 & 3.92 & 2.32 & 4.20 & 0.02 & 10.32 & 66 \\
\hline $4 / 12 / 94$ & 5/15/95 & 132 & 3.47 & 2.54 & 3.52 & 0.02 & 10.32 & 34 \\
\hline 5/16/95 & 2/15/96 & 111 & 3.30 & 2.37 & 3.78 & 0.04 & 7.83 & 30 \\
\hline 2/16/96 & 6/30/97 & 156 & 4.74 & 1.79 & 4.78 & 0.15 & 9.00 & 2 \\
\hline
\end{tabular}




\section{Table VIII}

\section{Descriptive Statistics of $C_{B I}^{M I N}$ relative to $C_{B I}$ and $C_{E T}$}

$C_{B I}^{M I N}$ is the minimum price set by the Bank of Israel $(\mathrm{BI})$ for the auction. $C_{B I}$ is the average auction price. $C_{E T}$ is the price of the exchange traded (ET) option. $C_{E T}$ is calculated using method 1 (Table II). $\left|C_{B I}^{M I N} / C_{B I}-1\right|$ measures the percent $C_{B I}^{M I N}$ is lower than $C_{B I} \cdot\left|C_{B I}^{M I N} / C_{E T}-1\right|$ measures the percent $C_{B I}^{M I N}$ is lower than $C_{E T}$.

\begin{tabular}{|c|c|c|c|c|c|c|}
\hline \multicolumn{2}{|c|}{ Period } & \multirow[b]{2}{*}{$\mathrm{N}$} & \multicolumn{2}{|c|}{$\left|C_{B I}^{M I N} / C_{B I}-1\right|$} & \multicolumn{2}{|c|}{$\left|C_{B I}^{M I N} / C_{E T}-1\right|$} \\
\hline From & To & & Mean & S.D. & Mean & S.D. \\
\hline All samp & & 399 & 0.172 & 0.160 & 0.351 & 0.139 \\
\hline $12 / 4 / 94$ & $15 / 5 / 95$ & 132 & 0.062 & 0.084 & 0.318 & 0.125 \\
\hline $16 / 5 / 95$ & $15 / 2 / 96$ & 111 & 0.103 & 0.118 & 0.275 & 0.130 \\
\hline $16 / 2 / 96$ & $30 / 6 / 97$ & 156 & 0.314 & 0.125 & 0.432 & 0.113 \\
\hline
\end{tabular}




\section{FOOTNOTES}

1 See Demsetz (1968) and more recent studies by Christie and Huang (1994) and Huang and Stoll (1996) on the relationship between liquidity and bid-ask spreads.

${ }^{2}$ See also Kadlec and McConell (1994) and Amihud, Mendelson and Lauterbach (1997).

3 Leland (1985), Boyle and Vorst (1992) and Toft (1994) introduced transactions costs into the BS model. Their analysis, however, is concerned with the costs of trading the underlying asset and its effect on the option. We are concentrating on the liquidity of the option itself.

${ }^{4}$ Examples of illiquid options include options granted to executives, tailor-made OTC options, etc.

${ }^{5}$ Commercial banks offer non-standardized over-the-counter options issued sporadically depending on the demand for FX options.

${ }^{6}$ See the Appendix for a detailed description of the currency market in Israel.

${ }^{7}$ During the sample period there were no bidders in nine auctions of the ATMF options and in 105 auctions of the ATM three-month options.

${ }^{8}$ We use the average quotes, for the ET options, since most foreign exchange transactions are done at the "representative" rate, based on mid-day bank quotes.

${ }^{9}$ The bids submitted by the clients through branch offices of their banks are not known to the main office, which deals with the bank's own account (Chinese walls).

${ }^{10}$ We exclude ET options that violate the basic arbitrage (Merton's) conditions, since these violations are usually for out-of-the-money options that trade infrequently and are not synchronous with the exchange rate. Since the BI options are issued ATM or ATMF and are auctioned with a minimum price, the arbitrage conditions are never violated for these options. 
${ }^{11}$ Several banks that regularly participate in these auctions were asked to explain their lack of interest in the ATM options raised this point. This is also the reason why the Bank of Israel stopped recently issuing the ATM options.

12 We tested if there is a volatility "smile" for the options that we used. The test compares ISD of options which are out-of-the-money with options that are in-the-money. The following results indicate that there is no significant difference between ISDs of the options that were used for interpolation.

\begin{tabular}{|lcccc|}
\hline \hline & Out-of-the-money & In-the-money & t-value & p-value \\
\hline ISD & 0.0648 & 0.0617 & 1.27 & 0.20 \\
\hline
\end{tabular}

${ }^{13}$ Since we use transaction prices that blend bid and ask prices, it may be argued that the bid-ask spread can explain most of the illiquidity discount. However, as it turns out, the bid-ask spread in this market is rather narrow and its effect on our results is negligible. As described in the Appendix, in over 80 percent of the trades the effective bid-ask spread is one tick (half of it is about one percent of the premium). Even if we use two ticks, half of the spread for an average premium of 500 NIS would amount to two percent of the option premium, which will reduce the average discount from 21 percent to 19 percent.

${ }^{14}$ We also use two additional alternative inputs of the underlying exchange rate; the previous day FX rate and the next day FX rate. The need for these alternative inputs stems from a potential bias in our estimates due to a synchronization issue of the exchange rate with the option prices, when we use representative exchange rates set by the central bank reflecting mid-day transactions. The results are essentially the same as in Table III. 
15 It could be argued that there is a tax effect. Under the tax code, individuals are exempt from taxes on TASE securities but not on the BI options. Other market participants (corporations, money managers) are not exempt. However, since only a fraction of trading in the FX market is done by individuals, we believe that the tax effect is negligible and cannot explain the difference that we observe.

${ }^{16}$ This particular test was suggested to us by the referee.

17 The average daily volume on auction expiration days was 993 contracts, compared with 897 contracts on other days. The difference is statistically insignificant ( $p$-value of $0.287)$.

${ }^{18}$ Recently the central bank has dropped many of these restrictions. 